\title{
Marcas da cultura patriarcal na violência dos corpos femininos: Uma abordagem do Direito Fraterno por uma sociedade não (in) humana ${ }^{1}$
}

\author{
Marcas de la cultura patriarcal em la violencia de los cuerpos femeninos: \\ um enfoque del Derecho fraterno por uma sociedad no (in) humana
}

\author{
Brands of the patriarchal culture in the violence of the feminine bodies: An \\ approach of the Fraternal Right by a nonhuman society
}

\author{
Charlise Paula Colet Gimenez ${ }^{2}$ \\ Gabrielle Scola Dutra ${ }^{3}$ \\ Rosângela Angelin ${ }^{4}$
}

\begin{abstract}
${ }^{1}$ Artigo apresentado no II Seminário Latino-Americano de Estudos em Cultura - SEMLACult em Fóz do Iguaçu/PR, Brasil, 2018.

${ }^{2}$ Doutora em Direito e Mestre em Direito pela Universidade de Santa Cruz do Sul - UNISC. Especialista em Direito Penal e Processo Penal pela Universidade Regional do Noroeste do Estado do Rio Grande do Sul UNIJUÍ. Docente permanente do Programa de Pós-Graduação em Direito stricto sensu - Mestrado e Doutorado, e Graduação em Direito, todos da Universidade Regional Integrada do Alto Uruguai e Missões - URI, campus Santo Ângelo. Coordenadora do Curso de Graduação em Direito da URI. Líder do Grupo de Pesquisa: "Conflito, Direitos Humanos e Cidadania, cadastrado no CNPQ. Advogada. Atua no estudo do Crime, Violência, Conflito e Formas de Tratamento de Conflitos - conciliação, mediação, arbitragem e justiça restaurativa. Santo Ângelo, Rio Grande do Sul, Brasil. E-mail: charliseg@ santoangelo.uri.br.
\end{abstract}

${ }^{3}$ Mestranda em Direito pela Universidade Regional Integrada do Alto Uruguai e das Missões - URI, campus Santo Ângelo. Bolsista CAPES. Pós-graduanda em Filosofia na Contemporaneidade (Especialização) pela URISA. Graduada em Direito pela URI-SA. Membro do grupo de pesquisa: "Conflito, Direitos Humanos e Cidadania", cadastrado no CNPQ e vinculado ao Programa de Pós-Graduação Stricto Sensu em Direito, Mestrado e Doutorado da URI; Santo Ângelo, Rio Grande do Sul, Brasil; e-mail: gabriellescoladutra@gmail.com.

${ }^{4}$ Pós-Doutora nas Faculdades EST (São Leopoldo-RS). Doutora em Direito pela Universidade de Osnabrueck (Alemanha). Docente do Programa de Pós-Graduação stricto sensu Doutorado e Mestrado em Direito e da Graduação em Direito da Universidade Regional Integrada do Alto Uruguai e das Missões (URI), Campus Santo Ângelo-RS. Coordenadora dos Projetos de Pesquisa: "Direitos Humanos e Movimentos Sociais na Sociedade Multicultural", vinculado ao PPG Direito, acima mencionado. Coordena o Projeto de Extensão: "O lugar dos corpos das Mulheres na Sociedade: uma abordagem do corpo e da defesa pessoal". Líder do Grupo de Pesquisa registrado no CNPQ: "Direitos de Minorias, Movimentos Sociais e Políticas Públicas. Integrante do Núcleo de Pesquisa de Gênero da Faculdades EST. Integra a Marcha Mundial de Mulheres. Colaboradora em Projetos Sociais junto a Associação Regional de Desenvolvimento, Educação e Pesquisa (AREDE), Santo Ângelo, Rio Grande do Sul, Brasil. E-mail: rosangelaangelin@yahoo.com.br. 


\begin{abstract}
Resumo
A metateoria do Direito Fraterno contribui para a reflexão das realidades e promoção de espaços de alteridade a fim de que o reconhecimento da mulher seja garantido nas sociedades plurais e nos ordenamentos jurídicos. Tem-se a importância da fraternidade por apostar no desempenho de um papel político na interpretação e na transformação do mundo real, revelando um valor heurístico e uma eficácia prática. Se eliminada no cenário social, a fraternidade pode ser resgatada como meio de possibilitar o reconhecimento do outro e de sua alteridade. Justifica-se, portanto, a abordagem da violência dos corpos, a partir da cultura patriarcal, pelo estudo do Direito Fraterno, pois se trata de um Direito sensível, humano e fundamentado na fraternidade que exige o reconhecimento do amigo da humanidade, aquele que reconhece a mulher e possibilita que as relações sociais sejam pautadas na defesa dos Direitos Humanos e da humanidade como lugar comum.
\end{abstract}

Palavras-Chave: Cultura Patriarcal, Direito Fraterno, Mulher, violência dos corpos femininos.

\title{
Resumen
}

La teoría del Derecho Fraterno contribuye a la reflexión de las realidades y la promoción de espacios de alteridad a fin de que el reconocimiento de la mujer sea garantizado en las sociedades plurales y en los ordenamientos jurídicos. Se tiene la importancia de la fraternidad por apostar en el desempeño de un papel político en la interpretación y la transformación del mundo real, revelando un valor heurístico y una eficacia práctica. Si se elimina en el escenario social, la fraternidad puede ser rescatada como medio de posibilitar el reconocimiento del otro y de su alteridad. Se justifica, por lo tanto, el abordaje de la violencia de los cuerpos, a partir de la cultura patriarcal, por el estudio del Derecho Fraterno, pues se trata de un Derecho sensible, humano y fundamentado en la fraternidad que exige el reconocimiento del amigo de la humanidad, aquel que reconoce mujer y posibilita que las relaciones sociales sean pautadas en la defensa de los Derechos Humanos y de la humanidad como lugar común.

Palabras claves: Cultura Patriarcal, Derecho Fraterno, Mujer, violencia de los cuerpos femeninos.

\begin{abstract}
The metatheory of Fraternal Law contributes to the reflection of realities and the promotion of spaces of alterity so that the recognition of women is guaranteed in plural societies and in legal systems. One has the importance of the fraternity to bet on the performance of a political role in the interpretation and transformation of the real world, revealing a heuristic value and a practical effectiveness. If it is eliminated in the social scene, the fraternity can be rescued as a means to enable the recognition of the other and its otherness. It is therefore justified to approach the violence of the bodies, starting from the patriarchal culture, by the study of the Fraternal Right, because it is a sensitive, human right and based on the fraternity that requires the recognition of the friend of humanity, the one who recognizes the woman and enables social relations to be based on the defense of Human Rights and humanity as a commonplace.
\end{abstract}

Keywords: Patriarchal Culture, Fraternal Law, Woman, violence of the female bodies.

\section{Introdução}

A compreensão de conflito pode ser abarcada a partir de processos interacionais entre os seres humanos em uma dimensão individual ou coletiva dentro do organismo social, no sentido de que o conflito se perfectibiliza com as relações de intencionalidade. Com efeito, a presente pesquisa se edificará por meio de uma abordagem dedutiva, instruída por uma análise bibliográfica. No tocante à totalidade social, perante as relações entre os gêneros da 
pós-modernidade ${ }^{5}$, em uma sociedade multicultural ${ }^{6}$ e complexa, a ideia conflitiva possui um viés negativo, quando orientada pela violência potencializada pelo sistema patriarcal no que concerne à significação de papéis sociais entre os gêneros.

Nesse sentido, o sistema patriarcal se sedimenta a partir da construção de uma estrutura hierárquica e de poder que legitima, pela violência, a sobreposição dos direitos dos homens sob os direitos das mulheres, no instante em que perpetua a manutenção da violência como mecanismo de controle e dominação em face dos corpos femininos, ou seja, o sistema patriarcal impõe sob a mulher, a figura do Outro quando do vínculo com o conflito. Aliás, as relações hierárquicas de poder entre os gêneros tangenciam em um contexto histórico, político e social eivado por conflitos que forjam o reconhecimento e as identidades das mulheres.

Desse modo, o modelo patriarcal, ao longo do contexto histórico de dominação, constituiu o direito sobre os corpos das mulheres por meio da institucionalização de um controle político e da naturalização de uma divisão social de gênero regulada pela dinamicidade das relações de opressão do homem sob a mulher. Diante desse embate, o presente trabalho tem o objetivo de demonstrar a relevância social e jurídica do emprego da Metateoria do Direito Fraterno como possibilidade que se pauta na defesa dos Direitos Humanos e da humanidade como lugar comum, orientada por um movimento não-violento, o qual aposta na desconstrução dos espaços totalizados pela violência patriarcal em prol da ascensão de um mundo mais sensível, fraterno e humano que perfectibiliza a (res)significação de um reconhecimento recíproco de todos os integrantes do tecido social.

\section{Marcas da cultura patriarcal na violência dos corpos femininos}

A construção das relações interacionais entre os indivíduos no interior do organismo social está atrelada à ideia de conflito. Em outras palavras, o conflito é inerente às relações sociais, no sentido de que é imprescindível compreendê-lo em sua totalidade e significação.

\footnotetext{
${ }^{5} \mathrm{O}$ termo sociedade pós-moderna "[...] representa a passagem da sociedade antiga para a moderna (ou a evolução de uma para a outra), que teria iniciado no século XVIII, embora muitos autores a datem nos idos dos anos de 1950 à década de 70, e que se relaciona com evolução, progresso, desenvolvimento, globalização econômica, mundialização da economia, promovendo, dessarte, uma ruptura com a ordem social existente até então, no caso, a tradicional" (LYRA, 2011, p. 60).

6 “[...] o termo multiculturalismo é substantivo. Refere-se às estratégias e políticas adotadas para governar ou administrar problemas de diversidade e multiplicidade gerados pelas sociedades multiculturais. É usualmente utilizado no singular, significando a filosofia específica ou a doutrina que sustenta as estratégias multiculturais. Multicultural, entretanto, é, por definição, plural” (HALL, 2003, p. 83).
} 
Nesse diapasão, a respeito do conflito de gênero instituído pelo sistema patriarcal, a compreensão da estrutura conflitiva revela um horizonte epistêmico multifacetado, o qual tangencia uma abordagem a partir de várias perspectivas, tais que se perfectibilizam de acordo com as circunstâncias existentes na constituição do ambiente conflitivo. Ademais, o sistema patriarcal estabelece um conflito que é potencializado a partir de inteirações humanas frente a relações de poder, sendo que uma das partes é a que vem a influenciar e ditar o movimento da outra parte (SERPA, 1999, p. 25).

Nessa perspectiva, Julien Freund conceitua o conflito ao asseverar que:

O conflito consiste em um enfrentamento por choque intencionado entre dois seres ou grupos da mesma espécie, os quais manifestam em detrimento de outros, uma intenção hostil, em geral a respeito de um direito, e que para manter, afirmar ou reestabelecer o direito, tratam de romper a resistência do outro eventualmente pelo recurso da violência, motivo pelo qual pode levar ao aniquilamento físico do outro [tradução livre] (FREUND, 1995, p. 58).

Portanto, perante o conflito entre os gêneros, insta salientar que "[...] o patriarcado consiste num sistema que integra relações sociais hierárquicas e de dominação em que os homens detêm direitos e poderes negados às mulheres, o que as torna inferiores socialmente, com justificativas de cunho biológico e naturalístico" (HAHN in GIMENEZ; LYRA (Orgs.), 2016, p. 59). Nesse sentido, Rosângela Angelin reflete sobre a formação das identidades das mulheres e dos aspectos que a influenciam, denunciando a falsa fixidez do argumento naturalizante do espaço reservado às mulheres "[...] o que as relações patriarcais têm imposto como natural é a ideia de que as características biológicas (menstruar, engravidar, ter filhos, amamentar, entrar na menopausa) definem as mulheres e, portanto, estas são parte da natureza, devendo seguir as leis dela" (ANGELIN, 2017, p. 58-59).

Com efeito, certamente que as pessoas do sexo feminino e masculino são diferentes biologicamente, mas isso não pode servir de argumento para criar estereótipos, fixando papéis e identidades. Nessa senda, desconstruir as correntes patriarcais que aprisionam os corpos das mulheres, significa denunciar que a violência contra elas tangencia em um terreno da construção de papéis sociais orientados por uma divisão entre os gêneros, a qual "ela própria é fundamentada na divisão dos estatutos sociais atribuídos ao homem e à mulher" (BOURDIEU, 2002, p. 24).

Simone de Beauvoir, abstrai-se a concepção dos lugares reservados para os corpos das mulheres na sociedade, espaços esses sempre determinados pelos homens, ou seja, tem sido os homens que ditam a vida e a trajetória das mulheres, com o sendo o "segundo sexo" (BEAUVOIR, 2016). O patriarcado, como visto, age com uma lógica centrada no poder 
masculino, oprimindo e desprezando todas as mulheres que não se adaptam aos padrões de comportamento esperado. Isso anula qualquer diversidade de identidades femininas. Para Marcela Lagarde y de Los Ríos, esse processo de construção patriarcal tentando homogeneizar as identidades femininas, ou seja, deram às mulheres uma identidade idêntica, educando-as para um estereótipo essencial, que é muito parecido. Isso destrói a individualidade das mulheres, fator esse que é o núcleo da autonomia (LAGARDE Y DE LOS RÍOS, 2005, p. 68-69)

É nesse sentido, que se faz salutar o reconhecimento de que as identidades não são fixas, muito pelo contrário, são contingentes e podem ser transitórias, uma vez que suas construções são forjadas a partir de processos históricos e temporais, bem como por vivências conscientes e inconscientes que lhes concedem caráter de identidades inconclusas e mutáveis (ANGELIN, 2017, p. 54). O interessante é que, por serem inconclusas e mutáveis, as identidades podem ser revistas, reconstruídas e ressignificadas, levando-se, portanto, em consideração a espacialidade, temporalidade e vivências. No contexto de opressão contra as mulheres, o direito masculino, ou seja, o direito pensado e criado em sua maioria por homens, faz com que o sistema patriarcal se perpetue, no sentido de utilizar o determinismo biológico para justificar a submissão da mulher, mantendo-a no espaço privado, conforme asseveram Angelin, Maders e Busanello:

A naturalização dos papéis masculinos e femininos tem contribuído para a manutenção das mulheres na vida privada e dos homens na vida pública. Reflexo disso é perceptível na seara política, onde são tomadas as principais decisões voltadas para a regulamentação das relações humanas e onde as mulheres ainda possuem representatividade bastante acanhada, o que, de certa forma, acaba prejudicando a elaboração de normas que viabilizem a concretização de direitos voltados para a equiparação nas relações de gênero e a efetivação de outros tantos (ANGELIN; MADERS; BUSANELLO, 2018, p. 104).

Destarte, lançar um olhar sobre a zona de penumbra que norteia a história dos corpos das mulheres, revela que a violência foi legitimada e ardilosamente arquitetada com o intuito de não permitir a ascensão das mulheres nos espaços de tomadas de decisões, seja no espaço público, ou privado. Ademais, em consonância com tal pensamento, Vera Regina Pereira de Andrade argumenta:

A construção social do gênero se processa pela atribuição dicotômica e hierarquizada de predicados aos sexos, em cuja bipolarização não apenas são opostas qualidades masculinas às femininas, mas estas são inferiorizadas: racional/ emocional, objetivo/ subjetivo, concreto/ abstrato, ativo/ passivo, força/ fragilidade, virilidade/ recato, trabalho na rua/ no lar, público/ privado. O polo ativo é representado pelo homem-racional-ativo-forte-guerreiro-viril-trabalhador-público, o 
polo passivo é representado pela mulher-emocional-passiva-fraca-impotentepacífica-recatada-doméstica (ANDRADE, 2004, p. 84).

Percebe-se, nessa ótica, que a história das mulheres se concentra na compreensão da existência e significação de seus corpos dentro do organismo social civilizacional. Nesse diapasão, o contexto de vivência das mulheres sedimenta, conforme Pierre Bordieu, corpos são moldados por processos que fogem a estrutura consciente de percepção ou de apreciação e seguem um padrão hegemônico de estruturas históricas baseadas na ordem masculina (BOURDIEU, 2002, p. 06). Todavia, a divisão das estruturas dos espaços de vivência de mulheres e de homens promove um cenário de violência, ao passo que a mulher se encontra numa condição naturalizada de submissão, como propriedade do homem. Sobretudo, é cogente afirmar que o corpo da mulher como terreno de vivências e experiências, torna-se doutrinado pelo sistema patriarcal, ou seja, “[...] o mundo social constrói o corpo numa realidade sexuada e como depositário de princípios de visão e divisão sexualizantes" (BOURDIEU, 2002, p. 9).

Ao se abordar a questão da violência sobre os corpos das mulheres, não se pode olvidar a tortura, mutilações e mortes em massa que as mulheres, em especial, de camponesas europeias no período medieval sofrerem frente ao clima misógino da época:

\footnotetext{
Nessa época, a Igreja Católica buscava consolidar-se em um cenário no qual ainda havia muitas religiões pagãs que cultuavam deusas femininas, bem como havia um contexto em que cristãos denominados hereges não seguiam as determinações da Igreja, inclusive mulheres cristãs que não aceitavam a imposição patriarcal da Igreja e davam voz a suas ideias, participando também de espaços de poder nos cultos religiosos. Esse foi um período violento de torturas físicas, psíquicas e de extermínio, em especial de mulheres, realizado por Tribunais jurídicos da Santa Inquisição, numa época histórica conhecida como de caça às bruxas, o qual contribuiu profundamente para demarcar a formação de estereótipos femininos e identidades baseadas na submissão, violência e opressão das mulheres (GIMENEZ; ANGELIN, 2017, p. 250).
}

Como visto, esse período foi composto pela autorização da violência, destacando-se que, um pouco antes disso, o Direito Civil da época e o Direito Canônico já haviam autorizada que os maridos batessem em suas mulheres para manterem a ordem no lar. No ano de 2016, depois de muita luta de Movimentos Feministas e de mulheres, mas, especialmente, por um ato punitivo de caráter internacional, o Brasil cria a Lei Maria da Penha, a fim de coibir a violência doméstica e familiar contra as mulheres e outras legislações pertinentes a outros tipos de violências (GIMENEZ; ANGELIN, 2017).

Em suma, constata-se que ser mulher na sociedade vigente é ter imposto sobre os corpos um estereótipo que, sob o leito da cultura patriarcal tem gerado violências, em 
especial, sobre os corpos das mulheres, sendo essas justificadas das mais variadas maneiras e anunciado cenários caóticos de violações sexuais, violência doméstica e familiar e outros tantos tipos de violência contra as mulheres. Por isso, urge a necessidade de se construir alternativas de mudança dessas relações a fim de se ter uma sociedade mais humanizada. Dessa forma, a próxima seção irá apresentar uma análise do Direito Fraterno como uma possibilidade de humanização dessas relações.

\section{Uma abordagem do Direito fraterno por uma sociedade não (in) humana}

A partir do contexto político e social da Revolução Francesa iniciada em 1789, a fraternidade surge como integrante do lema do movimento juntamente com a liberdade e a igualdade. Nesse período, a fraternidade era compreendida como um elemento de solidariedade entre as nações, no sentido de que tangenciava outras nações, do povo de uma nação, ao povo de outras nações. Destarte, se constituía como valor de potencialização do cosmopolitismo, ao passo que era delimitada pela manutenção nos domínios de estado de pertencimento às comunidades nacionais (RESTA, 2004).

Posteriormente, na sua análise conceptiva a fraternidade era entendida como um sentimento de proximidade com o próximo. No entanto, permanecia instrumentalizada pelo modelo de Estado-Nação atrelado à cidadania. Nessa conjuntura, a fraternidade constituía uma compreensão embasada nas relações com as gerações futuras, porém, ainda dentro das fronteiras das comunidades nacionais. Doutro modo, a fraternidade era representada pelo primado da amizade sobre a justiça, no que condiz que o ponto mais alto da justiça pertença à amizade. Nesse sentido, a amizade é compreendida como uma interação nas relações pessoais na forma de solidariedade, bem como no contato das trocas e intercâmbios sociais que fomentam a construção de laços tanto na igualdade como na diferença (RESTA, 2004).

A partir de tais premissas, constata-se a necessidade de uma transcendência do modelo de amizade para os domínios da fraternidade. Com efeito, insta salientar a imprescindibilidade de evidenciar a relação entre o direito e a fraternidade como espaço interseccional que perfectibilize os direitos humanos com a naturalização de uma consciência crítica. Sobretudo, o local onde se reconhece e se legitima os Direitos Humanos de todos, um reconhecimento que produza a diferença como potencializadora do respeito recíproco. Nesse sentido, o sentimento de fraternidade é alicerçado como dinâmica, a qual ultrapassa o "ser homem" e abre um caminho que integre a ideia de "ser humanidade". Portanto, a concepção de 
humanidade elaborada pela Metateoria do Direito Fraterno vem de encontro com a responsabilidade dos seres humanos no viés dos Direitos Humanos (RESTA, 2004).

Em consonância com a espistemologia desenvolvida pelo Direito Fraterno, é cogente asseverar que a humanização das relações sociais perpassa por movimentos humanos de sensibilidade e reconhecimento. Diante disso, o Direito Fraterno é uma possibilidade heurística que inicia um processo de auto-responsabilização com o Outro. Portanto, o Direito Fraterno se pauta em uma concepção de que "[...] não acredita na violência legítima, destitui o código dual do amigo-inimigo e acredita na jurisdição mínima e na adoção de meios menos violentos de tratamento de conflitos" (GIMENEZ; PIAIA, 2017, p. 94).

Dessa maneira, o Direito Fraterno traz à baila a significação do amigo da humanidade, quando desconstrói a carga forjadora que orienta o código amigo/inimigo no interior das relações conflitivas em prol de novos horizontes emancipadores. Não obstante, no que concerne ao conflito de gênero existente na sociedade atual, a fraternidade surge como aposta em um lugar comum, ou melhor, um espaço do "nós" que convive com as diferenças de maneira pacífica e conecta "mundos distantes".

Diante disso, Fábio Comparato, assevera no que concerne a igualdade entre os gêneros perante uma sociedade multicultural, a qual é pautada na diversidade que,

[...] todos os seres humanos, apesar das inúmeras diferenças biológicas e culturais que os distinguem entre si, merecem igual respeito. Como únicos entes no mundo capazes de amar, descobrir a verdade e criar a beleza. E o reconhecimento universal de que, em razão dessa radical igualdade, ninguém - nenhum indivíduo, gênero, etnia, classe social, grupo religioso ou nação - pode afirmar-se superior aos demais (COMPARATO, 2003, s.p.).

Por isso, é imprescindível rechaçar toda e qualquer manifestação de violência implementada pela cultura patriarcal dominante. Nessa perspectiva, um olhar sobre a história da violência contra os corpos das mulheres comprova a necessidade de desconstruir os papéissociais impostos pelo patriarcado à figura feminina. Destarte, o estudo do Direito Fraterno permite (re) estabelecer os vínculos amistosos de humanidade nas relações entre os gêneros. Logo, apostar na fraternidade é correr o risco de buscar caminhos não percorridos (próximos e/ou distantes) no reconhecimento das singularidades de cada ser humano, é um bem que transcende quando concretiza a humanidade como lugar comum. Sobretudo, é reconhecer todos os integrantes do tecido social, apostar na paz sem violência quando se alcança a diferença pelo novo em uma comunhão de pactos entre sujeitos concretos.

Sobretudo, aposta-se no Direito Fraterno como resgate da fraternidade compreendida como valor humano universal de defesa dos direitos das mulheres, no que concerne a 
possibilidade de reconhecimento do amigo da humanidade, aquele que reconhece a mulher em toda a sua existencialidade. Em conformidade com tal proposição, sob a perspectiva do conflito entre os gêneros a aplicabilidade do Direito Fraterno se fundamenta como "[...] um pacto de hospitalidade e assimilação, acolhimento e integração do outro - como meio de tratamento dos novos conflitos da pós-modernidade" (GIMENEZ; PIAIA, 2017, p. 77).

Com efeito, a Metateoria do Direito Fraterno:

[...] propõe uma nova possibilidade de olhar e estabelecer relações na sociedade por meio de um modelo em que a Justiça não seja a aplicação de regras frias, mas esteja atrelada a uma moral compartilhada entre iguais, ou seja, um modelo de sociedade cuja amizade seja entendida como relação pessoal e como forma de solidariedade (GIMENEZ; PIAIA, 2017, p. 93).

Nesse rumo, Alain Touraine afirma: "Eu sou uma mulher" significa que sou eu mesma enquanto mulher, enquanto ao redor de minha identidade de mulher se constroem minhas condutas e os julgamentos de valor que faço delas: positivos quando reforçam minha consciência de ser primeiramente uma mulher, (TOURAINE, 2007, p. 28). Em outras palavras, diante das marcas da cultura patriarcal na violência dos corpos femininos, tem-se a relevância da fraternidade, justamente por apostar em uma sociedade humana que descarta todas as possibilidades do emprego da violência quando da dinâmica das relações entre os gêneros, no sentido de "[...] sermos muito mais íntegros nos confrontos com o outro. Essa é uma forma de poder sentirmos desde o sentimento do outro, integrando-nos ao sentimento do outro" (WARAT, 2004, p. 28).

Sobretudo, a pacificação do conflito passa pelo crivo de um diálogo não-violento que se fundamenta no respeito e no reconhecimento da mulher pelo emprego da alteridade, bem como na compreensão da humanidade como lugar comum, igualmente possibilita que as relações sociais sejam pautadas na defesa dos Direitos Humanos, extinguindo a lógica perversa do Conflito amigo/inimigo ao permitir um encontro amistoso entre os gêneros. Por derradeiro, “[...] defende-se a necessidade de proteção aos direitos fundamentais da pessoa pela paz em um tecido social pluralista e democrático, o qual permita a reestruturação do sistema de administração da justiça sob a ótica da humanização" (GIMENEZ; SPENGLER, 2016, p. 80).

Por conseguinte, a fraternidade, como metadireito, tem um papel decisivo e importante na concretude de realidades, contribuindo por meio de interpretação e reflexões rumo a transformação prática do cotidiano, baseado em ressignificação de conceitos como amor e sensibilidade (GIMENEZ, 2018). 


\section{Considerações Finais}

Ao se analisar a sociedade envolvente, alicerçada em uma cultura patriarcal hegemônica, muitas vezes, frente a misoginia, resultando estados de violência latente contra as mulheres - violência física, moral, psíquica, social, laboral, assédios, entre outras formas, paira a dúvida se o cenário é humano ou não. Ou, minimamente, lança ao questionamento de como tornar as relações entre as pessoas, mais humanas.

A breve pesquisa realizada denota a força da cultura patriarcal na formação das identidades, tanto femininas, quanto masculinas, ou seja, na tentativa de fixidez de estereótipos tidos como corretos e, por conseguinte, ideais a serem seguidos. Esses padrões são influenciados pelas relações de poder que são produzidas pelo sistema patriarcal, influenciando, inclusive, em normas jurídicas opressoras ou estereotipantes. Fissuras desse cenário patriarcal tem sido constantemente exploradas por movimentos feministas que buscam reconhecimento identitário e redistribuição de renda para as mulheres. Muitos avanços jurídicos já foram alcançados, em especial, em países do ocidente, não se podendo afirmar que os mesmos se transmutaram em transformações culturais. Embora muitas mulheres tenham galgado espaços no mundo público e se emancipado parcialmente da cultura patriarcal, à mulher tem sido reservado um espaço secundário, menos importante na sociedade, além de sofrer os mais variados tipos de violência, sendo-lhes retirados ou não positivados certos direitos humanos.

Não obstante, a Metateoria do Direito Fraterno fomenta a transformação dos conflitos sociais por um equilíbrio ecológico. Dessa forma, a fraternidade apresenta-se como despolarizadora do ambiente conflitivo. Ao passo que, os estudos teóricos sobre o Direito Fraterno e suas premissas que constituem uma proposta de vivências sociais podem contribuir muito para a melhoria das relações entre os seres humanos, em especial por trazer a baila a necessidade da alteridade (reconhecimento do outro como integrante do tecido social pluralista) entre as pessoas. Isso denota mudanças não somente nas legislações, mas também na cultura da sociedade e, nesse caso, no fim da cultura patriarcal, gerando novos paradigmas humanos e, quem sabe, humanizando mais as pessoas.

Ao que pese o fato da metateoria do Direito Fraterno ser uma aliada nos debates contra todo e qualquer tipo de violência contra mulheres e, em prol da construção de uma sociedade mais justa e fraterna, sob o alicerce do encontro entre os seres humanos, não se pode 
simplesmente crer que uma teoria resolverá os problemas da humanidade. As teorias, a exemplo do Direito Fraterno, são importante instrumentos para reflexão e, ao mesmo tempo, servem como indicativos para a construção de uma sociedade mais humana.

\section{Referências}

ANDRADE, Vera Regina Pereira de. A soberania patriarcal: O Sistema de Justiça Criminal no tratamento da violência sexual contra a mulher. Boletim IBCCRIM, São Paulo, v. 1, n. 137, abr.

2004.

Disponível em: $\leq$ https://periodicos.ufsc.br/index.php/sequencia/article/view/15185/13811〉. Acesso em: 05 abr. 2018.

ANGELIN, Rosângela. Mulheres e ecofeminismo: Uma abordagem voltada ao desenvolvimento sustentável. Revista Universidad en Diálogo. Vol. 7, N. ${ }^{\circ} 1$, Enero-Junio 2017, pp. 51-68. Disponível em: <file:///C:/Users/Rosangela/Downloads/9512Texto\%20del\%20art\%C3\%ADculo-30186-1-10-20170630\%20(3).pdf >. Acesso em: 18 jul. 2018.

ANGELIN, Rosângela; MADERS, Angelita Maria; BUSANELLO, Elisabete. Mulheres no espaço público: complexidades, desafios e limitações. In: VERONESE, Osmar; ANGELIN, Rosângela [Orgs.]. Direito de Minorias, Movimentos Sociais e Políticas Públicas. Santo Ângelo/RS: FuRI, 2018, p. 103-118.

BEAUVOIR, Simone. O segundo sexo: fatos e mitos. 3. ed.. Rio de Janeiro: Nova Fronteira, 2016.

BOURDIEU, Pierre. A dominação masculina. $2^{\mathrm{a}}$ ed., Rio de Janeiro: Bertrand Brasil, 2002.

COMPARATO, Fábio Konder. A Afirmação histórica dos direitos humanos. 3 ed. rev. e ampl. São Paulo: Saraiva, 2003.

FREUND, Julien. Sociología del conflicto. Traduccion de Juan Guerrero Roiz de la Parra. Madrid: Ministério de Defensa, Secretaria General Técnica, D.I.., 1995.

GIMENEZ, Charlise Paula Colet. O novo no Direito de Luis Alberto Warat: Mediação e Sensibilidade. Curitiba: Juruá, 2018.

GIMENEZ, Charlise Paula Colet. PIAIA, Thami Covatti. O tratamento dos novos conflitos na pós-modernidade pelo direito fraterno: crises, migrações e insurgências. Revista Novos Estudos Jurídicos. Vol. 22. N. 1. Jan./abr. 2017. Disponível em: <https://siaiap32.univali.br/seer/index.php/nej/article/view/10633/5970>. Acesso em: 10 jun. 2018.

GIMENEZ, Charlise Paula Colet; ANGELIN, Rosângela. O conflito entre os Direitos Humanos, cultura e religião sob a perspectiva do estupro contra mulheres no Brasil. In: Revista Direito em Debate. v. 26. n. 46 (2017). Disponível em: 
〈https://www.revistas.unijui.edu.br/index.php/revistadireitoemdebate/article/view/6922>.

Acesso em: 06 Dez. 2018.

GIMENEZ, Charlise Paula Colet. SPENGLER, Fabiana Marion. O mediador na resolução 125/2010 do CNJ: um estudo a partir do Tribunal Múltiplas Portas. Águas de São Pedro: Livro Novo, 2016

HAHN, Noli Bernardo. Um direito com sabor de injustiças e humilhações: um ensaio relacionando hermenêutica de gênero e direitos humanos. In: GIMENEZ, Charlise Paula Colet. LYRA, José Francisco Dias da Costa. Diálogo e entendimento: Direito, Multiculturalismo \& políticas de cidadania e resolução de conflito: tomo 7. Campinas, SP: Millennium Editora, 2016, p. 51-70.

HALL, Stuart. Da diáspora: identidades e mediações culturais. SOVIK, Liv (Org.) Belo Horizonte: Editora UFMG.

LAGARDE Y DE LOS RÍOS, Marcela. Para mis socias de la vida. Madrid: horas y HORAS, 2005.

LYRA, José Francisco Dias da Costa. A expansão do Direito Penal na Pós-Moderna Sociedade do Risco: O Controle Penal e suas (im) possibilidades. In: (Re) Pensando Direito. V. $1.2011 . \quad N^{\circ} \quad 2.2$ P. 55-78. Disponível em: <http://local.cnecsan.edu.br/revista/index.php/direito/article/view/34>. Acesso em: 24 jun. 2018.

RESTA, Elígio. O Direito Fraterno: Direito e sociedade Contemporânea. Santa Cruz do Sul: EDUNISC, 2004.

SERPA, Maria de Nazareth. Teoria e Prática da Mediação de Conflitos. Rio de Janeiro: Lumen Juris, 1999.

TOURAINE, Alain. O mundo das mulheres. Petrópolis, Rio de Janeiro: Vozes, 2007.

WARAT, Luis Alberto. Surfando na pororoca: ofício do mediador. Florianópolis: Fundação Boiteux, 2004. 